\title{
Получение и исследование каталитической активности шунгита, модифицированного наночастицами меди
}

\author{
Ярцев С.Д ${ }^{1}$, Милюшкин А.Л ${ }^{1}$., Хесина 3.Б ${ }^{1}$., Ревина А.А ${ }^{1}$, \\ Суворова O.B ${ }^{1}$, Рёсснер $\Phi^{2}$., Петухова Г.А ${ }^{1}$., Буряк А.К ${ }^{1}$. \\ ${ }^{1}$ Институт физической химии и электрохимии им. А.Н.Фрумкина РАН, Москва \\ ${ }^{2}$ Университет им. Карла фон Осецкого, Ольденбург, Германия
}

Поступила в редакцию 31.01.2017 г.

\begin{abstract}
Разработан материал на основе природного минерала шунгита с нанесенными на его поверхность наночастицами меди. Рассмотрены закономерности адсорбции наночастиц из обратномицеллярных растворов шунгитом. Каталитические свойства полученного материала изучены на примере реакции карбонильных соединений с первичными аминами. Проведено сравнение шунгита, модифицированного наночастицами меди, с шунгитом, импрегнированным медью.
\end{abstract}

Ключевые слова: шунгит, наночастицы меди, катализ.

\section{Synthesis and study of catalytical activity of shungite modified with copper nanoparticles}

\author{
Iartsev S.D ${ }^{1}$., Milyushkin A.L ${ }^{1}$., Khesina Z.B ${ }^{1}$., Revina A.A ${ }^{1}$., \\ Souvorova O.V ${ }^{1}$., Roessner F. ${ }^{2}$, Petukhova G.A ${ }^{1}$., Buryak A.K ${ }^{1}$. \\ ${ }^{I}$ A.N. Frumkin Institute of Physical Chemistry and Electrochemistry, Russian Academy of Sciences, Moscow \\ ${ }^{2}$ Carl v. Ossietzky University, Oldenburg, Germany
}

Carrying out a large number of processes in organic synthesis requires the use of expensive catalysts based on palladium, gold, silver and other metal nanoparticles. Numerous studies have focused on a search of systems that have a similar catalytic action, but lower cost. The development of catalysts based on various carbon sorbents modified with copper nanoparticles seems to be promising. Natural mineral shungite is a cheap and readily available raw carbon material, which occurrs only in Russia. This article focuses on the use of shungite as a carrier for a catalyst based on copper nanoparticles.

A known method for the synthesis of nanoparticles in reverse micellar solutions was applied to the synthesis of copper nanoparticles. A model catalyst, obtained by adsorption of nanoparticles from solutions on shungite material, was studied in this work. The catalyst was characterized by electron microprobe analysis and UV-visible spectroscopy. The activity of the catalyst obtained was evaluated by the model reaction of primary amines with carbonyl compounds.

Keywords: shungite, copper nanoparticles, catalysis.

\section{Введение}

Шунгит - природный минерал, добываемый в Карелии и содержащий в своём составе от 0.1 до 98\% масс. углерода, до 70\% масс. силикатов, а также разные количества соединений железа, алюминия, магния, марганца и серы. 
Благодаря своим свойствам, экологической безопасности и огромным запасам месторождений, шунгит находит широкое применение в различных областях промышленности. Особое место занимают исследования, посвященные каталитическим свойствам шунгита и материалов на его основе $[1,2]$. Наночастицы металлов широко используются для катализа в сочетании с углеродными материалами. Ввиду востребованности и дороговизны производства катализаторов на основе палладия и других благородных металлов, представляет интерес разработка новых систем, с использованием медных наночастиц, не уступающих в каталитической активности, но в то же время не требующих использования драгоценных металлов. В литературе описано большое число различных процессов, катализируемых медными наночастицами: синтез триазолов [3-6], арилирование фенолов (реакция Ульмана) [7, 8], аза-реакция Михаэля [9], синтез енаминонов [10], окисление спиртов [11] и другие. Для изготовления подобных катализаторов используются различные углеродные носители. Целью настоящей работы является оценка возможностей применения шунгита как основы для катализаторов. В настоящем исследовании разработан материал на основе шунгита с нанесенными на его поверхность наночастицами меди и изучены его каталитические свойства на примере взаимодействия аминов с карбонильными соединениями.

\section{Эксперимент}

Приборы и материалы. В работе использовались коммерчески доступные реактивы фирм Sigma и Merck, без последующей очистки. Для синтеза наночастиц использовали изооктан, натриевую соль бис-(2-этилгексил) сульфосукцината (АОТ), кверцетин (3,5,7,3',4'-пентагидроксифлавон), сульфат меди, водный раствор аммиака. Для оценки каталитической активности исследуемых материалов применяли метанол, бутанон, ацетилацетон, анилин, сорбент МСМ-41. В работе использовали шунгит Зажогинского месторождения, подробно изученный в работе [12]. Для измельчения образцов шунгита использовали шаровую мельницу, для получения механоактивированного шунгита использовали планетарную мельницу. Рентгеноспектральный микроанализ выполняли на микроанализаторе Camebax (Cameca, Франция). Изображения исследуемых материалов получали с помощью растровой приставки к микроанализатору Camebax (Cameca, Франция). Спектры оптического поглощения регистрировали с использованием спектрофотометра Hitachi U3900, в кварцевых кюветах с длиной оптического пути 1 мм. Хроматографическое разделение выполняли на газовом хроматографе НР 5890, с колонкой НР-1701.

Синтез наночастиц $\mathrm{Cu}$. Восстановление ионов $\mathrm{Cu}^{2+}$ до $\mathrm{Cu}^{0}$ в обратно мицеллярной системе выполняли по методике, описанной в [13]. К мицеллярному раствору (система 55 мкМ кверцетин - 0.15 М АОТ - изооктан) добавляли водный раствор $\mathrm{Cu}\left(\mathrm{NH}_{3}\right)_{4} \mathrm{SO}_{4}$ (получаемый добавлением соответствующего количества аммиака к водному раствору сульфата меди). Концентрация соли $\mathrm{Cu}$ в мицеллярном растворе составляла $4.1 \mathrm{мM}$, степень гидратации $\mathrm{w}=\left[\mathrm{H}_{2} \mathrm{O}\right] /[\mathrm{AOT}]$ составляла 5. Для контроля протекания процесса синтеза наночастиц меди проводили спектрофотометрический анализ, наблюдали появление характерной полосы поглощения в области 542-545 нм.

Приготовление катализатора. К раствору наночастиц $\mathrm{Cu}$ добавляли измельченный шунгит, интенсивно перемешивали, выдерживали в течение 30 минут, после чего раствор фильтровали, остаток высушивали и использовали в последующих экспериментах. 
Импрегнирование МСМ-41 медью. К 1 г МСМ-41 по каплям добавляли 1 см 0.1 мМ раствора нитрата меди. Полученный материал прокаливали в муфельной печи при $160^{\circ} \mathrm{C}$, после чего нагревали над потоком водорода и сразу использовали.

Синтез енаминона. В пробирку на $10 \mathrm{~cm}^{3}$ с завинчивающейся крышкой помещали смесь ацетилацетона (1 ммоль), анилина (2 ммоль) и метанол $\left(4 \mathrm{~cm}^{3}\right)$. К реакционной смеси добавляли шунгит, модифицированный наночастицами меди. Смесь выдерживали при $50^{\circ} \mathrm{C}$ при постоянном перемешивании. Ход реакции контролировали методом газовой хроматографии. Для контроля хода реакции пробы из реакционной смеси отбирали, фильтровали и вводили в газовый хроматограф.

\section{Обсуждение результатов}

Для модифицирования шунгита наночастицами меди 1 г измельченного шунгита выдерживали в $10 \mathrm{~cm}^{3}$ синтезированного раствора, содержащего наночастицы меди. Для контроля протекания процесса адсорбции наночастиц меди на поверхности шунгита проводили спектрофотометрический анализ надосадочной жидкости (рис. 1). По уменьшению интенсивности полосы поглощения в области 542-545 нм делали вывод о протекании процесса адсорбции. Установили, что адсорбция проходит практически полностью в течение 30 минут.

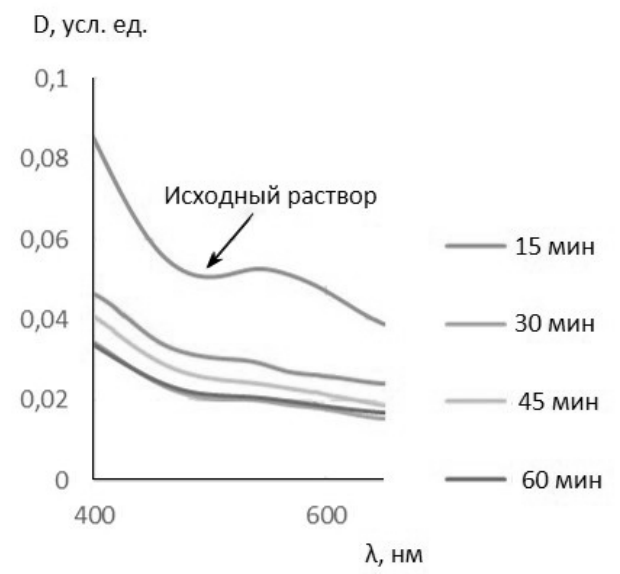

Рис. 1. Спектры оптического поглощения растворов наночастиц меди, находящихся в контакте с шунгитом в течение 15, 30, 45 и 60 минут, а также исходного раствора наночастиц меди.

Также исследовали, как размер частиц шунгита влияет на эффективность адсорбции. Опробовали шунгит с размером частиц 75-150 мкм, 150-180 мкм, 180250 мкм и 250-500 мкм (размер определялся просеиванием через соответствующие сита). Показали, что для частиц меньшего размера адсорбция протекает с большей скоростью, однако если адсорбция проходит в течение 1 дня, то разница в эффективности адсорбции оказывается не принципиальной (рис. 2). После прохождения адсорбции в течение 1 дня модифицированный шунгит высушивали на воздухе.

Для подтверждения присутствия меди в модифицированных образцах шунгита был проведен рентгено-спектральный микроанализ (РСМА). Согласно его результатам (рис. 3), содержание меди в полученном материале составляет 7.5\% (масс.). В немодифицированном шунгите содержание меди составляло менее $0.5 \%$. Исходя из полученных данных, можно заключить, что предложенный способ обработки шунгита может быть использован для модифицирования шунгита наночастицами меди. 
С помощью растрового электронного микроскопа получены изображения шунгита, модифицированного наночастицами меди (рис. 4).

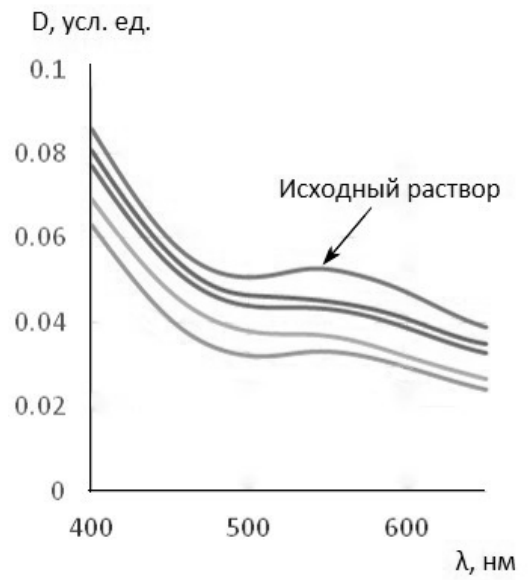

a

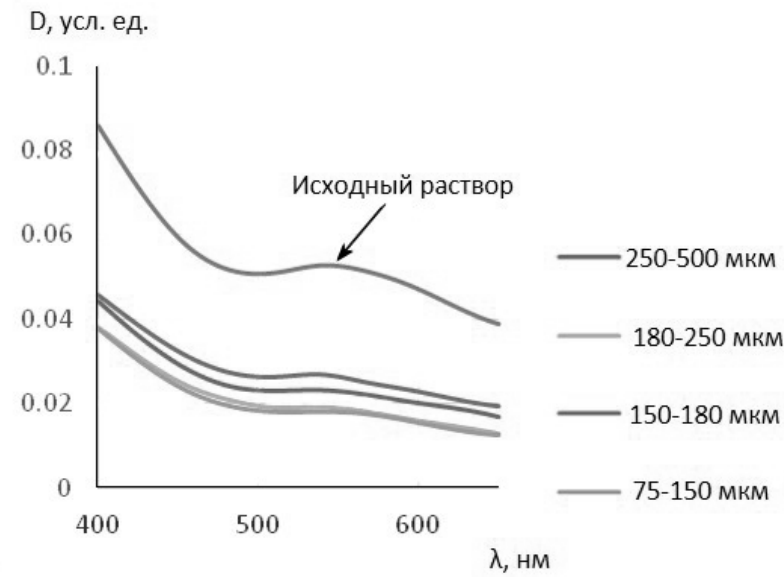

б

Рис. 2. Спектры оптического поглощения растворов наночастиц меди, находящихся в контакте с шунгитом с частицами разного размера (75-150, 150-180, 1

80-250, 250-500 мкм), а также спектр исходного раствора наночастиц меди.

Время проведения адсорбции - 30 минут (а) и 1 сутки (б).

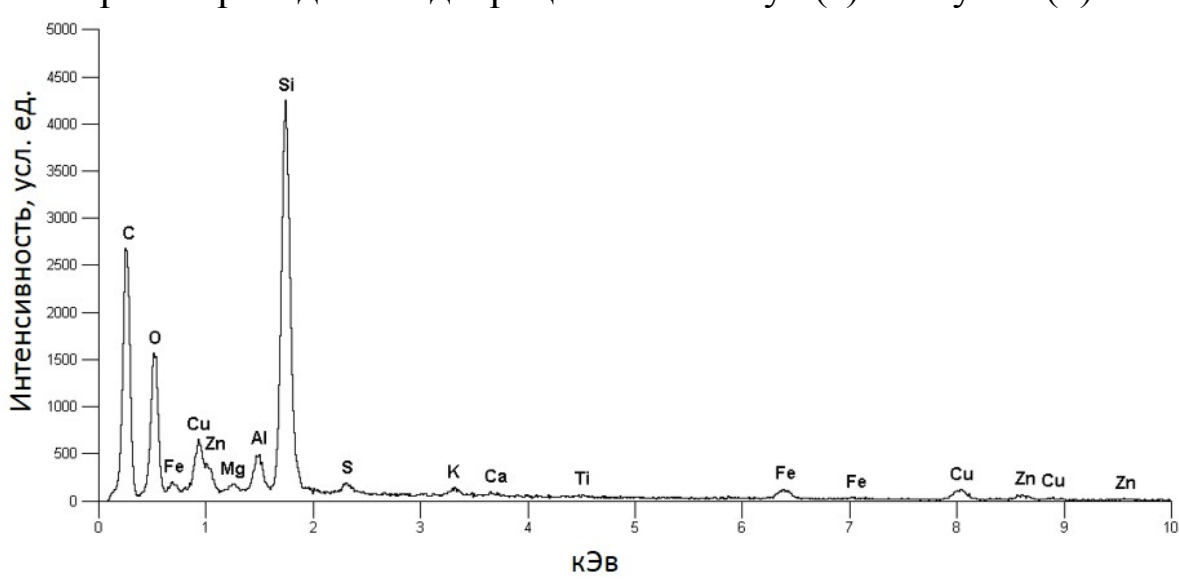

Рис. 3. Результат рентгено-спектрального микроанализа шунгита, модифицированного наночастицами меди.
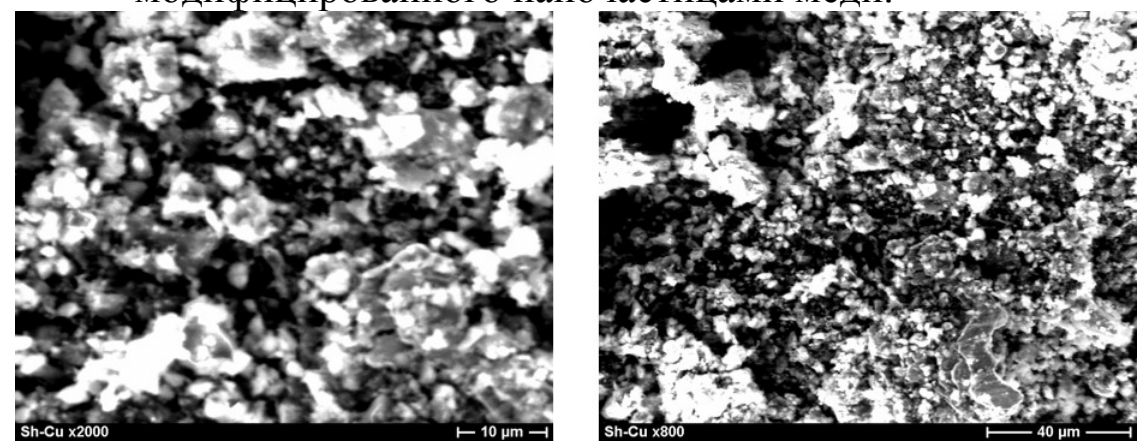

Рис. 4. Изображения шунгита, модифицированного наночастицами меди, полученные с помощью растрового электронного микроскопа. Увеличение в 2000 раз (слева) и в 800 раз (справа).

В качестве исследуемой реакции для проверки каталитической активности полученного шунгита, модифицированного наночастицами меди, было выбрано взаимодействие карбонильных соединений с первичными аминами. Для оценки ско- 
рости реакции в различных условиях проводили кинетические исследования, выход продукта реакции находили как отношение площади пика продукта к площади пика карбонильного соединения, находящегося в недостатке. Результаты обобщены в табл. 1. Показано, что в случае взаимодействия бутанона и анилина предпочтительным является использование метанола в качестве растворителя, повышение температуры приводит к повышению выхода продукта. Использование бензойной кислоты не позволяет повысить выход реакции, равно как и применение сорбента МСМ-41 и шунгита (а в случае, если эти материалы импрегнированы медью, реакция протекает значимо медленнее). Наибольший выход (31.4\%) удается достичь, проводя реакцию в среде метанола, при $50^{\circ} \mathrm{C}$, без добавления кислоты или сорбента. Таким образом, использование шунгита, модифицированного наночаситцами меди, не позволяет увеличить выход реакции бутанона с анилином.

Таблица 1. Выходы реакции бутанона с анилином при различных температурах, используемых растворителях и катализаторах

\begin{tabular}{|c|c|c|c|}
\hline Температура, ${ }^{\circ} \mathrm{C}$ & Растворитель & Катализатор & Выход, 24ч, \% \\
\hline 25 & - & - & 15.6 \\
\hline 25 & - & Бензойная кислота & 17.8 \\
\hline 25 & - & МСМ-41 & 15.2 \\
\hline 25 & - & МСМ-41, импрегнированный $\mathrm{Cu}$ & 14.7 \\
\hline 25 & $\mathrm{MeOH}$ & - & 24.8 \\
\hline 25 & $\mathrm{MeOH}$ & Бензойная кислота & 26.2 \\
\hline 50 & $\mathrm{MeOH}$ & - & 31.4 \\
\hline 50 & $\mathrm{MeOH}$ & Шунгит & 27.7 \\
\hline 50 & $\mathrm{MeOH}$ & Шунгит, импрегнированный $\mathrm{Cu}$ & 22.0 \\
\hline
\end{tabular}

Далее исследовали взаимодействие анилина с дикарбонильным соединением, ацетилацетоном. Эта реакция катализируется кислотами, однако в литературе описан синтез енаминонов в присутствии наночастиц меди, без добавления кислоты [14]. Схема реакции выглядит следующим образом:<smiles>CC(=O)CC(C)=O</smiles>

Из-за наличия двух карбонильных групп в молекуле ацетилацетона реакция идет лучше, чем в случае с бутаноном, и приводит к образованию не имина, а енаминона, вследствие большей устойчивости структуры с 1,3-сопряжением. В работе сравнивались различные условия проведения реакции: растворитель, температура, наличие кислоты, добавка мезопористого сорбента МСМ-41, шунгита. В целом, в течение 24 часов практически при всех опробованных условиях выход реакции оказался выше $90 \%$, в таблице 2 приведены выходы реакции за 90 минут в зависимости от условий проведения.

Можно отметить, что использование метанола в качестве растворителя повышает выход реакции, оптимальная температура проведения реакции составляет $50^{\circ} \mathrm{C}$, однако увеличение выхода оказывается не столь значительным, поэтому все последующие эксперименты проводились при $25^{\circ} \mathrm{C}$. Добавление кислоты позволяет значительно повысить скорость реакции (фактически, реакция протекает количественно уже в течение 1 часа). Кинетические кривые реакций в случае добавления сорбента МСМ-41 к реакционной смеси приведены на рис. 5. Можно заключить, что 
МСМ-41 замедляет реакцию, но в случае, если МСМ-41 импрегнирован медью - реакция замедляется еще значительнее.

Таблица 2. Выходы реакции ацетилацетона с анилином при различных температурах, используемых растворителях и катализаторах

\begin{tabular}{|c|c|c|c|}
\hline $\begin{array}{c}\text { Температура, } \\
{ }^{\circ} \mathrm{C}\end{array}$ & Растворитель & Катализатор & $\begin{array}{c}\text { Выход, 90 мин, } \\
\%\end{array}$ \\
\hline 25 & - & - & 35.9 \\
\hline 25 & $\mathrm{MeOH}$ & - & 46.5 \\
\hline 50 & $\mathrm{MeOH}$ & - & 58.0 \\
\hline 25 & $\mathrm{MeOH}$ & Бензойная кислота & 99.6 \\
\hline 25 & $\mathrm{MeOH}$ & МСМ-41 & 36.7 \\
\hline 25 & $\mathrm{MeOH}$ & МСМ-41, импрегнированный $\mathrm{Cu}$ & 22.7 \\
\hline 25 & $\mathrm{MeOH}$ & Шунгит & 15.2 \\
\hline 25 & $\mathrm{MeOH}$ & Шунгит, импрегнированный $\mathrm{Cu}$ & 69.0 \\
\hline 25 & $\mathrm{MeOH}$ & Шунгит, модифицированный & 19.6 \\
\hline
\end{tabular}

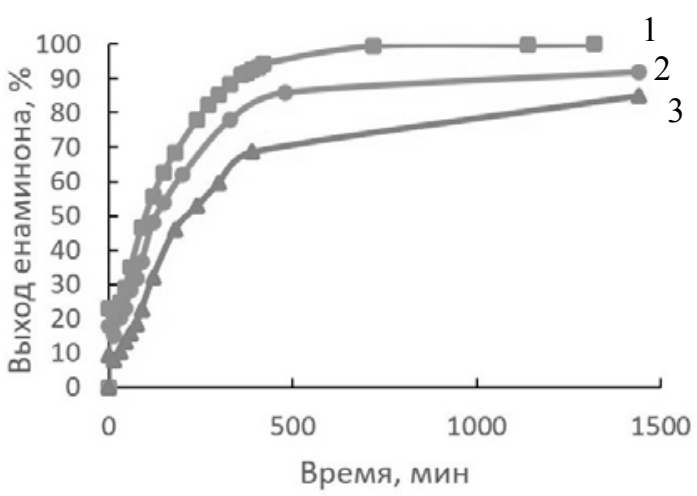

Рис. 5. Кинетические кривые реакции ацетилацетона с анилином без добавления сорбента (1), с добавлением MCM-41(2) и с добавлением МСМ41, импрегнированного медью(3)

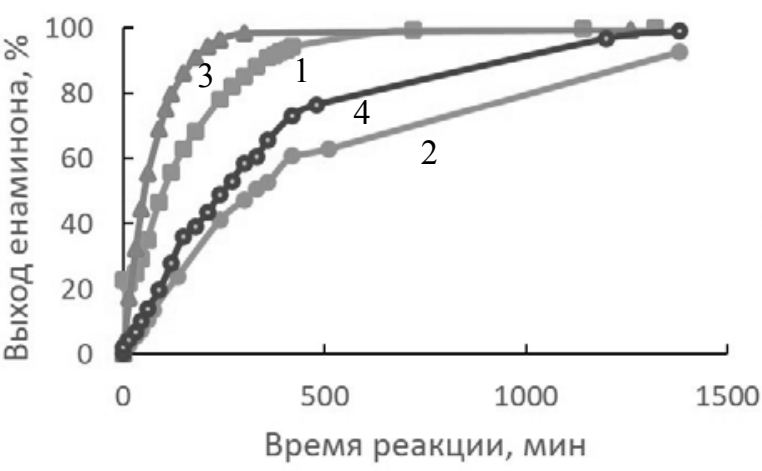

Рис. 6. Кинетические кривые реакции ацетилацетона с анилином без добавления шунгита (1), с добавлением шунгита(2), с добавлением шунгита, импрегнированного медью(3) и с добавлением шунгита, модифицированного наночастицами меди(4)

Исследовалось влияние шунгита на описываемую реакцию. Соответствующие кинетические кривые приведены на рис. 6. Так же, как и в случае с МСМ-41, добавление шунгита замедляет реакцию, однако использование шунгита, импрегнированного медью, позволяет значительно увеличить скорость реакции (выход реакции за 90 минут составил $69 \%$, что является наилучшим результатом, за исключением того, в котором к реакционной смеси добавлялась бензойная кислота). Однако использование шунгита, модифицированного наночастицами меди, не позволило добиться более высоких выходов. Это может быть вызвано несовершенством процедуры синтеза катализатора, в частности, с его поверхности не удалялся избыток АОТ. Также при приготовлении шунгита, модифицированного наночастицами меди, не проводили термическую обработку и обработку нагретым водородом (как в случае приготовления шунгита, импрегнированного медью). 


\section{Заключение}

Таким образом, в работе предложен подход к созданию катализатора на основе шунгита, модифицированного наночастицами меди. Полученный материал охарактеризован методами спектрофотометрии и РСМА. Оценена каталитическая активность материала в реакциях первичных аминов с карбонильными соединениями. Полученный модельный катализатор не позволяет повысить скорость и выход в исследованных реакциях. Это может быть вызвано несовершенством процедуры синтеза катализатора, в частности, с его поверхности не удалялся избыток АОТ, не проводили термическую обработку и обработку нагретым водородом. Влияние этих стадий подготовки катализатора на его эффективность требуют дальнейшего исследования.

Работа выполнена в рамках 7 Рамочной Программы ЕС по конкурсу FP7-PEOPLE-IRSES и при финансовой поддержке РФФИ (грант 15-08-08006)

\section{Список литературы}

1. Токпаев Р.Р., Нечипуренко С.В., Аккужиев А.С., Ефремов С.А., и др.// Вестник КазНУ. Серия химическая. 2011. №4 (64). С. 193-196.

2. Токпаев Р.Р., Атчабарова А.А., Кабулов А.Т., Кишибаев К.К. и др. // Вестник КазHTУ. 2015. № 5. C. 412-418.

3. Sharghi H., Khalifeh R., Doroodmand M.M. // Adv. Synth. Catal. 2009. Vol. 351. pp. 207-218. Doi: 10.1002/adsc.200800612

4. Alonso F., Moglie Y., Radivoy G., Yus M. // Tetr. Lett. 2009. Vol. 50. pp. 2358-2362. Doi:10.1016/j.tetlet.2009.02.220

5. Park I.S., Kwon M.S., Kim Y., Lee J.S. Park J. // Org. Lett. 2008. Vol. 10. No. 3. pp. 497-500. Doi: 10.1021/o1702790w

6. Sarkar A., Mukherjee T., Kapoor S. // J. Phys. Chem. C. 2008. Vol. 112. pp. 3334-3340. Doi: $10.1021 / \mathrm{jp} 077603 \mathrm{i}$

7. Kidwai M., Kumar N. M., Bansal V., Kumar A. et al. // Tetr. Lett. 2007. Vol. 48. pp. 8883-8887. Doi:10.1016/j.tetlet.2007.10.050

8. Isomura Y., Narushima T., Kawasaki H., Yonezawab T. et al. // Chem. Commun. 2012.

\section{References}

1. Tokpayev R.R., Nechipurenko S.V., Akkuzhyev A.S., Yefremov S.A. et al., KazNU Bull. Chem., 2011, No 4 (64), pp. 193-196.

2. Tokpayev R.R., Atchabarova A.A., Kabulov A.T., Kishibayev K.K. et al., KazNTU Bull., 2015, No 5, pp. 412-418.
Vol. 48. pp. $\quad 3784-3786$. Doi: $10.1039 / \mathrm{c} 2 \mathrm{cc} 30975 \mathrm{k}$

9. Verma A.K., Kumar R., Chaudhary P., Saxena A. et al. // Tetr. Lett. 2005. Vol. 46. pp. 5229-5232. doi:10.1016/j.tetlet.2005.05.108

10. Kidwai M., Bhardwaj S., Kumar N. M, Bansal V. et al. // Catalysis Comm. 2009. Vol. $10 . \quad$ pp. 1514-1517. doi:10.1016/j.catcom.2009.04.006

11. Mitsudome T., Mikami Y., Ebata K., Mizugaki T. et al. // Chem. Commun. 2008. Vol. 39. pp. 4804-4806. 10.1039/B809012B

12.Голуб С.Л., Ульянов А.В., Буряк А.К., Луговская И.Г. и др. // Сорбиионные и хроматографические прочессы. 2006. Т. 6. № 5. C. 748-763.

13. Ревина А.А. Патент РФ, № 2322327 , 2006.

14.Bhatte K.D., Tambade pp.J., Dhake K.pp., Bhanage B.M. // Catalysis Comm. 2010. Vol. $11 . \quad$ pp. 1233-1237. Doi:10.1016/j.catcom.2010.06.011

3. Sharghi H., Khalifeh R., Doroodmand M.M., Adv. Synth. Catal., 2009, Vol. 351, pp. 207-218. DOI: $10.1002 /$ adsc. 200800612

4. Alonso F., Moglie Y., Radivoy G., Yus M., Tetrahedron Letters, 2009, Vol. 50, pp. 23582362. doi:10.1016/j.tetlet.2009.02.220 
5. Park I.S., Kwon M.S., Kim Y., Lee J.S. et al., Org. Lett., 2008, Vol. 10, No 3, pp. 497-500. Doi: $10.1021 / \mathrm{ol} 702790 \mathrm{w}$

6. Sarkar A., Mukherjee T., Kapoor S.,/ J. Phys. Chem. C. 2008, Vol. 112, pp. 3334-3340. Doi: 10.1021/jp077603i

7. Kidwai M., Kumar N.M., Bansal V., Kumar A. et al., Tetr. Lett., 2007, Vol. 48, pp. 8883-8887. Doi:10.1016/j.tetlet.2007.10.050

8. Isomura Y., Narushima T., Kawasaki H., Yonezawab T. et al., Chem. Commun., 2012, Vol. 48, pp. 3784-3786. Doi: $10.1039 / \mathrm{c} 2 \mathrm{cc} 30975 \mathrm{k}$

9. Verma A.K., Kumar R., Chaudhary P., Saxena A. et al., Tetr. Lett., 2005, Vol. 46, pp. 5229-5232. doi:10.1016/j.tetlet.2005.05.108

Ярцев Степан Дмитриевич - аспирант 2 года обучения, ИФХЭ РАН, Москва

Милюшкин Алексей Леонидович - аспирант 2 года обучения, ИФХЭ РАН, Москва.

Хесина Зоя Борисовна - инженерисследователь, ИФХЭ РАН, Москва.

Ревина Александра Анатольевна - профессор, д.Х.н., ведущий научный сотрудник, ИФХЭ РАН, Москва.

Суворова Ольга Валентиновна - научный сотрудник, ИФХЭ РАН, Москва

Рёсснер Франк - профессор кафедры технической химии университета им. Карла фон Осецкого, Ольденбург, Германия.

Петухова Галина Анатольевна - к.х.н., заведующая лабораторией, ИФХЭ РАН, Москва

Буряк Алексей Константинович - професcop, д.х.н., заведующий лабораторией физикохимических основ хроматографии и хроматомасс-спектрометрии, ИФХЭ РАН, Москва
10.Kidwai M., Bhardwaj S., Kumar N. M, Bansal V. et al., Catalysis Comm., 2009,. Vol. 10 , $\mathrm{pp}$.

1514-1517.

doi:10.1016/j.catcom.2009.04.006

11.Mitsudome T., Mikami Y., Ebata K., Mizugaki T. et al., Chem. Commun., 2008, Vol. 39, pp. 4804-4806. 10.1039/B809012B

12.Golub S.L., Ulyanov A.Vol., Buryak A.K., Lugovskaja I.G. et al., Sorbtsionnye i khromatograficheskie protsessy, 2006, Vol. 6, No 5, pp. 748-763.

13. Revina A.A. Patent RF, no 2322327, 2006.

14.Bhatte K.D., Tambade pp.J., Dhake K.P., Bhanage B.M., Catalysis Comm., 2010, Vol. 11, pp. 1233-1237.

Doi:10.1016/j.catcom.2010.06.011

Iartsev Stepan Dmitrievich - PhD student of the $2 \mathrm{~d}$ year, IPCE RAS, Moscow. yartsew1@yandex.ru

Milyushkin Aleksey Leonidovich - PhD student of the 2d year, IPCE RAS, Moscow

Khesina Zoya Borisovna -research engineer, IPCE RAS, Moscow

Revina Aleksandra Anatol'evna - professor, the chief scientific worker, IPCE RAS, Moscow

Souvorova Olga Valentinovna - scientific worker, IPCE RAS, Moscow

Roessner Frank - Prof. Dr., Chair of Industrial Chemistry 2, Institute of Pure and Applied Chemistry, Carl v. Ossietzky University, Oldenburg, Germany

Petukhova Galina Anatol'evna - PhD, the head of the laboratory, IPCE RAS, Moscow

Buryak Aleksey Konstantinovich - Professor, the head of Laboratory of physical-chemical bases of chromatography and mass-spectrometry, IPCE RAS. Moscow 